\title{
Hyperkalemia in heart failure patients in Spain and its impact on guidelines and recommendations: ESC-EORP-HFA Heart Failure Long-Term Registry
}

Hiperpotasemia en pacientes con insuficiencia cardiaca en España y su impacto en las recomendaciones. Registro ESC-EORP-HFA Heart Failure Long-Term

María G. Crespo-Leiro, ${ }^{\text {a,b }}$ Eduardo Barge-Caballero, ${ }^{\text {a,b }}$ Javier Segovia-Cubero, ${ }^{\text {b,c }}$ José González-Costello, ${ }^{\mathrm{d}}$ Silvia López-Fernández, ${ }^{\mathrm{e}}{ }^{\mathrm{a}}$ osé Manuel García-Pinilla, ${ }^{\text {b.f }}$ Luis Almenar-Bonet, ${ }^{\mathrm{g}}$ Javier de Juan-Bagudá, ${ }^{\mathrm{h}}$ Eulalia Roig-Minguell, ${ }^{\mathrm{b}, \mathrm{i}}$ Antoni Bayés-Genís, ${ }^{\mathrm{b}, \mathrm{j}}$ Marisa Sanz-Julve, ${ }^{\mathrm{k}}$ José Luis Lambert-Rodríguez, ${ }^{1}$ Antonio LaraPadrón, ${ }^{\mathrm{m}}$ José María Pérez-Ruiz, ${ }^{\mathrm{n}}$ Carla Fernández-Vivancos Marquina, ${ }^{\circ}$ Luis de la Fuente-Galán, ${ }^{\mathrm{p}}$ Alfonso Varela-Román, ${ }^{\mathrm{b}, \mathrm{q}}$ Francisco Torres-Calvo, ${ }^{\mathrm{r}}$ Javier Andrés-Novales, ${ }^{\mathrm{s}}$ Aida Escudero-González, ${ }^{\mathrm{t}}$ Domingo A. Pascual-Figal, ${ }^{\mathrm{b}, \mathrm{u}}$ Francisco Ridocci-Soriano, ${ }^{\mathrm{v}}$ Ana Sahuquillo-Martínez, ${ }^{\mathrm{w}}$ David Bierge-Valero, ${ }^{\mathrm{x}}$ Francisco Epelde-Gonzalo, ${ }^{\mathrm{y}}$ Juan Carlos Gallego-Page, ${ }^{\mathrm{z}}$ Regina Dalmau González-Gallarza, ${ }^{\text {,aa }}$ Ramón Bover-Freire, ${ }^{\mathrm{b}, \mathrm{ab}}$ Juan Quiles-Granado, ${ }^{\mathrm{ac}}$ Aldo Pietro Maggioni, ${ }^{\text {ad,ae }}$ Lars H. Lund, ${ }^{\text {af }}$ JavierMuñiz, ${ }^{\text {bag }}$ Juan Delgado-Jiménez. ${ }^{\text {b, }}$

${ }^{a}$ Unidad de Insuficiencia Cardiaca y Trasplante, Servicio de Cardiología, Instituto de Investigación Biomédica de A Coruña (INIBIC), Complexo Hospitalario Universitario de A Coruña (CHUAC), SERGAS, Universidade da Coruña (UDC), A Coruña, Spain

${ }^{b}$ Centro de Investigación Biomédica en Red de Enfermedades Cardiovasculares (CIBERCV), Instituto de Salud Carlos III, Madrid, Spain

${ }^{c}$ Unidad de Insuficiencia Cardiaca Avanzada, Trasplante e Hipertensión Pulmonar, Servicio de Cardiología, Hospital Universitario Puerta de Hierro, Majadahonda, Madrid, Spain

${ }^{d}$ Unidad de Insuficiencia Cardiaca Avanzada y Trasplante, Servicio de Cardiología, Hospital Universitari de Bellvitge-IDIBELL, L'Hospitalet de Llobregat, Barcelona, Spain

${ }^{e}$ Unidad de Insuficiencia Cardiaca, Servicio de Cardiología, Hospital Universitario Virgen de las Nieves, Granada, Spain

${ }^{f}$ Unidad de Insuficiencia Cardiaca y Cardiopatías Familiares, Unidad de Gestión Clínica de Cardiología y Cirugía Cardiovascular, Hospital Universitario Virgen de la Victoria, IBIMA, Málaga, Spain

${ }^{g}$ Unidad de Insuficiencia Cardiaca y Trasplante, Servicio de Cardiología, Hospital Universitario y Politécnico La Fe, Valencia, Spain

${ }^{h}$ Unidad de Insuficiencia Cardiaca y Trasplante, Servicio de Cardiología, Hospital Universitario 12 de Octubre, Madrid, Spain

${ }^{i}$ Unidad de Insuficiencia Cardiaca y Trasplante, Servicio de Cardiología, Hospital de la Santa Creu i Sant Pau, Barcelona, Spain

${ }^{j}$ Servicio de Cardiología, Hospital Universitario Germans Trias i Pujol, Badalona, Barcelona, Spain

${ }^{k}$ Unidad de Insuficiencia Cardiaca Avanzada y Trasplante, Servicio de Cardiología, Hospital Universitario Miguel Servet, Zaragoza, Spain

${ }^{l}$ Unidad de Insuficiencia Cardiaca Avanzada y Trasplante Cardiaco, Hospital Universitario Central de Asturias, Oviedo, Asturias, Spain 
${ }^{m}$ Servicio de Cardiología, Hospital Universitario de Canarias, Santa Cruz de Tenerife, Canarias, Spain

${ }^{n}$ Unidad Especializada de Insuficiencia Cardiaca, Servicio de Cardiología, Unidad de Gestión del Corazón y

Patología Vascular, IBIMA, Hospital Universitario Regional de Málaga, Málaga, Spain

${ }^{\circ}$ Servicio de Cardiología, Hospital Universitario Virgen Macarena, Sevilla, Spain

${ }^{p}$ Unidad de Insuficiencia Cardiaca Avanzada y Trasplante, Servicio de Cardiología, Hospital Clínico Universitario de Valladolid, Valladolid, Spain

${ }^{q}$ Unidad de Insuficiencia Cardiaca, Complexo Hospitalario Universitario de Santiago de Compostela (CHUS), SERGAS, Universidad de Santiago de Compostela (USC), Santiago de Compostela, A Coruña, Spain

${ }^{r}$ Unidad de Insuficiencia Cardiaca, Hospital Costa del Sol, Marbella, Málaga, Spain

${ }^{s}$ Servicio de Cardiología, Hospital San Eloy, Baracaldo, Vizcaya, Spain

${ }^{t}$ Servicio de Cardiología, Hospital Povisa, Vigo, Pontevedra, Spain

"Servicio de Cardiología, Hospital Universitario Virgen de la Arrixaca, IMIB-Arrixaca, Universidad de Murcia, El Palmar, Murcia, Spain

${ }^{v}$ Servicio de Cardiología, Consorcio Hospital General Universitario de Valencia, Valencia, Spain

${ }^{w}$ Servicio de Cardiología, Hospital de Manacor, Manacor, Balearic Islands, Spain

${ }^{x}$ Unidad de Insuficiencia Cardiaca, Servicio de Cardiología, Hospital Verge de la Cinta, Tortosa, Tarragona, Spain

${ }^{y}$ Unidad de Estancia Corta, Hospital Universitari Parc Taulí, Sabadell, Barcelona, Spain

${ }^{z}$ Servicio de Cardiología, Complejo Hospitalario de Albacete, Albacete, Spain

${ }^{a}$ Servicio de Cardiología, Hospital de Cantoblanco, Hospital Universitario La Paz, Madrid, Spain

${ }^{a b}$ Programa de Insuficiencia Cardiaca, Servicio de Cardiología, Hospital Universitario Clínico San Carlos, Madrid, Spain

${ }^{a c}$ Servicio de Cardiología, Hospital Universitario de San Juan, San Juan de Alicante, Alicante, Spain

${ }^{a d}$ Associazione Nazionale Medici Cardiologi Ospedalieri (ANMCO), Research Center, Florencia, Italy

${ }^{a e}$ EuroObservational Research Program (EORP), European Society of Cardiology (ESC), Sophia Antipolis, France

af Department of Medicine, Karolinska Institutet, y Heart and Vascular Theme, Karolinska University Hospital, Solna, Sweden

${ }^{a g}$ Universidade da Coruña, Instituto Universitario de Ciencias de la Salud, Instituto de Investigación Biomédica de A Coruña (INIBIC), A Coruña, Spain

\begin{abstract}
Introduction and objectives. Hyperkalemia is a growing concern in the treatment of patients with heart failure and reduced ejection fraction because it limits the use of effective drugs. We report estimates of the magnitude of this problem in routine clinical practice in Spain, as well as changes in potassium levels during follow-up and associated factors.

Methods. This study included patients with acute $(\mathrm{n}=881)$ or chronic $(\mathrm{n}=3587)$ heart failure recruited in 28 Spanish hospitals of the European heart failure registry of the European Society of Cardiology and followed up for 1 year. Various outcomes were analyzed, including changes in serum potassium levels and their impact on treatment.

Results. Hyperkalemia $\left(\mathrm{K}^{+}>5.4 \mathrm{mEq} / \mathrm{L}\right)$ was identified in $4.3 \%(95 \% \mathrm{CI}, 3.7 \%-5.0 \%)$ and $8.2 \%(6.5 \%$ $10.2 \%$ ) of patients with chronic and acute heart failure, respectively, and was responsible for $28.9 \%$ of all cases of contraindication to mineralocorticoid receptor antagonist use and for $10.8 \%$ of all cases of failure to reach the target dose. Serum potassium levels were not recorded in 291 (10.8\%) of the 2693 chronic heart failure patients with reduced ejection fraction. During follow-up, potassium levels increased in 179 of 1431 patients $(12.5 \%, 95 \% \mathrm{CI}, 10.8 \%-14.3 \%)$. This increase was directly related to age, diabetes, and history of stroke and was inversely related to history of hyperkalemia.

Conclusions. This study highlights the magnitude of the problem of hyperkalemia in patients with heart failure in everyday clinical practice and the need to improve monitoring of this factor in these patients due to its interference with the possibility of receiving optimal treatment.
\end{abstract}




\section{Resumen}

Introducción y objetivos. La hiperpotasemia es una preocupación creciente en el tratamiento de los pacientes con insuficiencia cardiaca y fracción de eyección reducida, pues limita el uso de fármacos eficaces. Este trabajo ofrece estimaciones de la magnitud de este problema en la práctica clínica habitual en España, los cambios en las concentraciones de potasio en el seguimiento y los factores asociados.

Métodos. Pacientes con insuficiencia cardiaca aguda $(\mathrm{n}=881)$ y crónica $(\mathrm{n}=3.587)$ seleccionados en 28 hospitales españoles del registro europeo de insuficiencia cardiaca de la European Society of Cardiology y seguidos 1 año para diferentes desenlaces, incluidos cambios en las cifras de potasio y su impacto en el tratamiento.

Resultados. La hiperpotasemia $\left(\mathrm{K}^{+}>5,4 \mathrm{mEq} / \mathrm{l}\right)$ está presente en el 4,3\% (IC95\%, 3,7-5,0\%) y el 8,2\% (6,5$10,2 \%$ ) de los pacientes con insuficiencia cardiaca crónica y aguda; causa el $28,9 \%$ de todos los casos en que se contraindica el uso de antagonistas del receptor de mineralocorticoides y el 10,8\% de los que no alcanzan la dosis objetivo. Del total de 2.693 pacientes ambulatorios con fracción de eyección reducida, 291 (10,8\%) no tenían registrada medición de potasio. Durante el seguimiento, 179 de 1.431 (12,5\%, IC95\%, 10,8-14,3\%) aumentaron su concentración de potasio, aumento relacionado directamente con la edad, la diabetes mellitus y los antecedentes de ictus e inversamente con los antecedentes de hiperpotasemia.

Conclusiones. Este trabajo destaca el problema de la hiperpotasemia en pacientes con insuficiencia cardiaca de la práctica clínica habitual y la necesidad de continuar y mejorar la vigilancia de este factor en estos pacientes por su interferencia en el tratamiento óptimo.

\section{Keywords}

Hyperkalemia; Heart failure; Real-world evidence; Follow-up

\section{Palabras clave}

Hiperpotasemia; Insuficiencia cardiaca; Registro de práctica clínica habitual; Seguimiento

\section{Abbreviations}

ACEI: angiotensin-converting enzyme inhibitor; ARB: angiotensin II receptor blocker; CHF: chronic heart failure; HF: heart failure; MRA: mineralocorticoid receptor antagonist; RAAS: renin-angiotensin-aldosterone system 


\section{INTRODUCTION}

In recent years, several mutually reinforcing factors have combined to increase the burden of heart failure (HF) in industrialized countries such as Spain, converting this disease into a major health problem. The burden of HF in Spain is predicted to increase further. ${ }^{1}$

This worsening situation has been paralleled by improvements in therapy, including effective treatments for deteriorated systolic function with drugs targeting the renin-angiotensin-aldosterone system (RAAS). Despite their inclusion in clinical practice guidelines, ${ }^{2,3}$ these treatments induce a $2-3$-fold increase in the risk of hyperkalemia in HF patients. ${ }^{3,4}$ Hyperkalemia is associated with conduction disorders and the risk of potentially fatal arrhythmias and is by no means a rare condition; estimates published 20 years ago already indicated a prevalence in hospitalized patients between $1 \%$ and $10 \% .^{5}$

More recent data indicate that $5.6 \%$ of patients within the first year of initiating therapy with angiotensin-converting enzyme inhibitors (ACEI) have potassium levels $>5 \mathrm{mmol} / \mathrm{L}$ and that $1.7 \%$ have potassium levels $>5.5 \mathrm{mmol} / \mathrm{L}{ }^{6}$ The high risk of hyperkalemia in HF patients is due not only to the medication they take, but also to the frequent presence of comorbidities such as chronic kidney disease and diabetes mellitus. ${ }^{7}$ The relationship between HF and chronic kidney disease is mutually reinforcing, and poor glomerular filtration rate is strongly associated with high HF prevalence. ${ }^{8}$ Moreover, a subanalysis of the RALES study found a higher risk of hyperkalemia in HF patients with a low estimated glomerular filtration rate at baseline and in those whose kidney function deteriorated during dose titration; the effect was even stronger in the subgroup randomized to spironolactone. ${ }^{9}$

Treatment with RAAS inhibitors is a class IA indication in clinical practice guidelines for patients with low ejection fraction. ${ }^{2,3}$ Because of the increasingly widespread use of these drugs, hyperkalemia is now a growing concern in the treatment of these patients.

Despite this situation, there is a lack of prospective studies estimating the magnitude of the hyperkalemia problem among chronic HF (CHF) patients in routine clinical practice in Spain. A recent cross-sectional study ${ }^{10}$ showed that 1 out of every 4 patients with an indication for mineralocorticoid receptor antagonists (MRA) did not receive this treatment. Of those who did, $3 / 4$ did not achieve the target dose. These data underline the importance of hyperkalemia, since this was the principal cause of nontreatment in $8.5 \%$ of untreated patients and the principal cause of failure to achieve the target dose in $10 \%$ of patients. ${ }^{10}$

Spain participates in the European Society of Cardiology (ESC) Heart Failure Long-Term registry (ESC-HF-LT-R), ${ }^{11}$ supplying between $1 / 4$ and $1 / 5$ of European patients included in the registry. ${ }^{10}$ This registry is a valuable resource for the study of hyperkalemia in the current HF patient population in Spain. The aim of the present study was to estimate the magnitude of the hyperkalemia problem in this population and to assess the contribution of hyperkalemia to the failure to achieve guideline-recommended doses. The study also assessed unique information about changes in potassium and associated factors during follow-up. 


\section{METHODS}

The ESC-HF-LT-R methodology has been described in detail previously, both in general and as applied in Spain. ${ }^{10,11}$ The 28 participating centers from Spain cover a range of complexity in the cardiology service offered. During the recruitment period, the registry included all HF outpatients older than 18 years attending the designated external consultation, as well as patients hospitalized on the same day with acute HF (de novo HF or acute decompensation of chronic disease) requiring intravenous therapy with intotropic, vasodilator, or diuretic drugs. The recruitment strategy changed over time, from 1 day per week during the first year of the registry to 5 consecutive days per trimester from the end of 2013. The registry is dynamic, in the sense that centers may have joined at different times and may therefore have included patients during distinct periods. In the present study, we analyzed data from patients included between July 2016 and December 2016.

Patients were monitored according to the standard practice at each participating center, except for an obligatory 12-month follow-up visit to collect information on mortality and morbidity. Patients unable to attend their designated health center were followed up by telephone consultation.

The ESC-HF-LT-R includes a quality assurance program involving audits of approximately $10 \%$ of participating centers, selected at random. In 2013, 2 of the participating Spanish centers were audited. The study was approved by the ethics committees of the participating centers, and all patients provided informed consent before inclusion.

Baseline information is presented for the acute $\mathrm{HF}$ and $\mathrm{CHF}$ groups. Patient situations and treatments during hospitalization are highly variable and can act as confounding factors that are difficult to control for. Therefore, we present complete follow-up information only for CHF patients with stable disease.

\section{Study definitions}

$\mathrm{K}^{+}$concentration was stratified according to widely established clinical thresholds: normal, $\mathrm{K}+\leq$ $5 \mathrm{mEq} / \mathrm{L}$; mildly elevated, between 5.1 and $5.4 \mathrm{mEq} / \mathrm{L}$; moderately elevated, between 5.5 and 5.9 $\mathrm{mEq} / \mathrm{L}$, and severely elevated, $\geq 6 \mathrm{mEq} / \mathrm{L}$. Hypokalemia was defined as $\mathrm{K}+<3.5 \mathrm{mEq} / \mathrm{L}$ and hyperkalemia as $\mathrm{K}+>5.4 \mathrm{mEq} / \mathrm{L}$. Hospitalized patients were diagnosed with hyperkalemia or hypokalemia if they had at least one $\mathrm{K}^{+}$determination during hospitalization $>5.4 \mathrm{mEq} / \mathrm{L}$ or $<3.5$ $\mathrm{mEq} / \mathrm{L}$, respectively. Patients were considered to have a history of renal disease if their medical records included a serum creatine determination $>1.5 \mathrm{mg} / \mathrm{dL}$. Renal function in study participants was assessed by glomerular filtration rate estimated with the MDRD formula (Modification of Diet in Renal Disease); glomerular filtration rate was classified as normal or mildly decreased ( $\geq$ $\left.60 \mathrm{~mL} / \mathrm{min} / 1.73 \mathrm{~m}^{2}\right)$, mildly to moderately decreased $\left(30-59 \mathrm{~mL} / \mathrm{min} / 1.73 \mathrm{~m}^{2}\right.$ ), or severely decreased $\left(<30 \mathrm{~mL} / \mathrm{min} / 1.73 \mathrm{~m}^{2}\right)$. ${ }^{12} \mathrm{HF}$ with reduced ejection fraction was defined as $\mathrm{HF}$ accompanied by a left ventricular ejection fraction $\leq 40 \%{ }^{2,3}$

The ESC-HF-LT-R data-entry application calculates a target dose for each drug according to clinical practice guidelines. ${ }^{2}$ These were the doses used, with the exception of enalapril and carvedilol. In both cases, the dose calculated by the registry application has been superseded in more recent guidelines by lower recommended doses, decreasing from $40 \mathrm{mg} / \mathrm{d}$ to $10-20 \mathrm{mg} / \mathrm{d}$ for enalapril and from $100 \mathrm{mg} / \mathrm{d}$ to $50 \mathrm{mg} / \mathrm{d}$ for carvedilol. 


\section{Statistical analysis}

Continuous variables are presented as mean \pm standard deviation, and categorical variables are presented as percentages. Where appropriate, population estimates are presented together with $95 \%$ confidence intervals $(95 \% \mathrm{CI})$. Between-group comparisons were made by the Student $t$-test or the Fisher exact test, depending on the type of variable. Worsening $\mathrm{K}^{+}$profiles during follow-up were analyzed by logistic regression. Patients were considered to have a worsening $\mathrm{K}^{+}$profile if they were classified in a higher serum $\mathrm{K}^{+}$category on the 1-year follow-up visit than at baseline, according to the categories defined above. A retrograde multivariable model included age, sex, and factors identified in the univariable analysis with $P<.1$.

All data were analyzed centrally using the statistical package STATA 12.0.

\section{RESULTS}

Of the 5242 patients included on the Spanish registry as of March 10, 2017, 108 were excluded due to nonconfirmation of consent or incomplete information about disease type (acute vs chronic). A further 58 had died during hospitalization. Of the remaining 5076 patients, 4468 (88\%) were taking at least 1 potassium-altering medication at baseline (Figure 1). The baseline characteristics of the acute and chronic HF patient groups are summarized in Table 2. The 2 groups had markedly different profiles; the acute HF group was older, included more women, and had a higher proportion of patients with preserved ejection fraction. The acute HF group also had a generally higher prevalence of comorbidities, except for those related to a history of ischemic heart disease, which reflected the different HF etiologies in the 2 groups. 


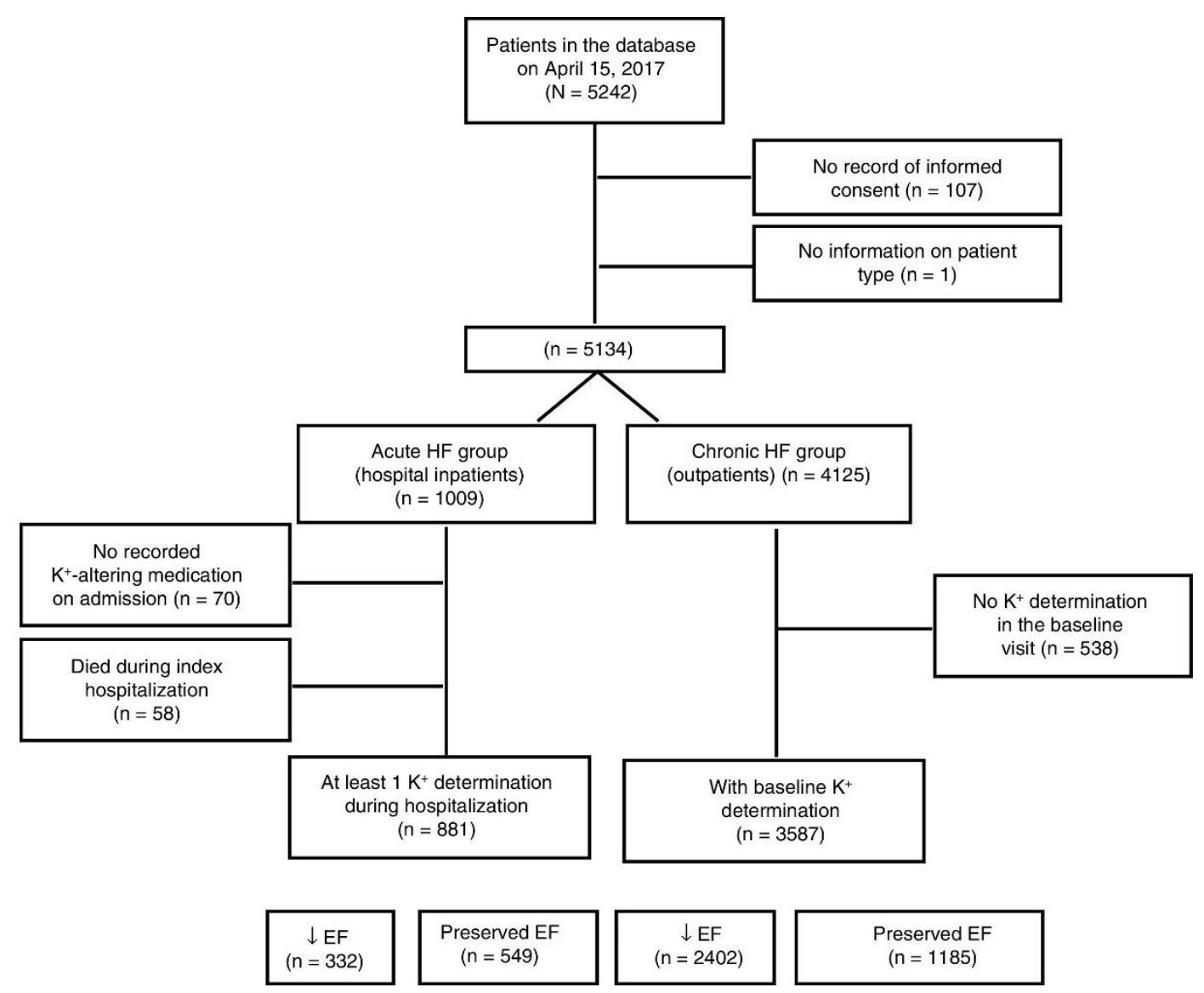

Figure 1. Patient flow chart. The figure of 2402 outpatients with reduced ejection fraction was obtained from the total of 2693 patients in this category by subtracting 291 patients with no $\mathrm{K}^{+}$determination. $\mathrm{EF}$, ejection fraction; HF, heart failure.

Table 2. Comparison of the baseline characteristics of patients with acute hf (inpatients) and with chronic HF (outpatients)

\begin{tabular}{llll}
\hline & Acute HF & Chronic HF & $P$ \\
\hline Patients, $n$ & & & \\
Age, $y$ & 881 & 3587 & \\
Age group & $75 \pm 12.4$ & $64.4 \pm 12.7$ & $<.001$ \\
$\quad<60$ y & & & \\
60-69y & 12.0 & 33.1 & \\
$70-79$ y & 16.2 & 29.7 & \\
M 80 y & 29.2 & 26.2 & $<.001$ \\
Men & 42.7 & 11.1 & \\
Smoking status & 54.3 & 71.2 & \\
Current smoker & & & \\
Exsmoker & 9.1 & 9.5 & \\
$\quad$ Nonsmoker & 33.5 & 48.9 & .001 \\
Patient history & 57.4 & 41.6 & .009 \\
Atrial fibrillation & & & \\
Diabetes mellitus & 49.7 & 35.5 & \\
Angina & 41.3 & 35.8 &
\end{tabular}




\begin{tabular}{|c|c|c|c|}
\hline Surgical revascularization & 6.7 & 8.7 & .051 \\
\hline Percutaneous revascularization & 17.5 & 24.8 & $<.001$ \\
\hline Stroke/transient ischemic attack & 11.8 & 8.1 & .001 \\
\hline Peripheral vascular disease & 11.4 & 11.2 & .906 \\
\hline Valve surgery & 7.7 & 11.2 & .002 \\
\hline Hypertension & 70.9 & 56.2 & $<.001$ \\
\hline Venous thromboembolism & 1.5 & 1.3 & .657 \\
\hline Chronic obstructive pulmonary disease & 22.7 & 14.6 & $<.001$ \\
\hline Renal disease & 26.7 & 17.5 & $<.001$ \\
\hline Cancer & 9.3 & 5.8 & $<.001$ \\
\hline Congestive hepatopathy & 2.7 & 2.6 & .858 \\
\hline Depression & 8.4 & 9.2 & .465 \\
\hline Parkinson & 1.0 & 0.4 & .012 \\
\hline Arthritis & 1.7 & 1.3 & .373 \\
\hline Estimated glomerular filtration rate MDRD & $\begin{array}{l}53.4 \pm 23.9(n= \\
876)\end{array}$ & $\begin{array}{l}71.0 \pm 30.6(\mathrm{n} \\
=3558)\end{array}$ & $<.001$ \\
\hline Categories & & & $<.001$ \\
\hline Severely decreased $\left(<30 \mathrm{~mL} / \mathrm{min} / 1.73 \mathrm{~m}^{2}\right)$ & 16.4 & 6.1 & \\
\hline $\begin{array}{l}\text { Mildly to moderately decreased }(30-59 \\
\left.\mathrm{mL} / \mathrm{min} / 1.73 \mathrm{~m}^{2}\right)\end{array}$ & 48.7 & 29.8 & \\
\hline Normal or mildly decreased $\left(\geq 60 \mathrm{~mL} / \mathrm{min} / 1.73 \mathrm{~m}^{2}\right)$ & 34.8 & 64.1 & \\
\hline Reduced ejection fraction $(\leq 40 \%)$ & 39.1 & 66.5 & $<.001$ \\
\hline Left ventricular ejection fraction, $\%$ & $46.85 \pm 15.98$ & $37.41 \pm 13.72$ & $<.001$ \\
\hline HF etiology & & & $<.001$ \\
\hline Dilated cardiomyopathy & 17.0 & 32.9 & \\
\hline HF syndrome with preserved ejection fraction & 5.9 & 0.8 & \\
\hline Hypertension & 17.0 & 5.2 & \\
\hline Ischemic heart disease (undocumented) & 6.0 & 2.1 & \\
\hline Ischemic heart disease (documented) & 25.3 & 36.3 & \\
\hline Tachycardia-induced cardiomyopathy & 3.4 & 1.6 & \\
\hline Valve disease & 17.4 & 9.6 & \\
\hline Other & 8.0 & 11.5 & \\
\hline Diuretic therapy & 81.6 & 80.4 & .415 \\
\hline Type & & & $<.001$ \\
\hline Chlorthalidone & 0.7 & 0.5 & \\
\hline Furosemide & 92.6 & 78 & \\
\hline Hydrochlorothiazide & 2.2 & 2.4 & \\
\hline Indapamide & 0.1 & 0.4 & \\
\hline Torasemide & 4.3 & 18.6 & \\
\hline Other & 0 & 0.1 & \\
\hline
\end{tabular}

HF, heart failure; MDRD, Modification of Diet in Renal Disease.

Unless indicated otherwise, data are expressed as \% or mean \pm standard deviation.

Serum potassium distribution and the prevalence of hyperkalemia in the 2 patient groups are shown in Table 3. The prevalence of hyperkalemia in acute HF patients was almost double that in CHF patients. 
Table 3. Baseline potassium distribution and prevalence of hyperkalemia $\left(\mathrm{K}^{+}>5.4 \mathrm{mEq} / \mathrm{L}\right)$ in patients with acute HF and chronic HF

\begin{tabular}{|c|c|c|c|c|c|c|}
\hline \multirow[t]{2}{*}{ Serum potassium } & \multicolumn{3}{|c|}{ Chronic heart failure } & \multicolumn{3}{|c|}{ Acute heart failure } \\
\hline & $\mathrm{n}=3587$ & $\%$ & $95 \% \mathrm{CI}$ & $\mathrm{n}=881^{*}$ & $\%$ & $95 \% \mathrm{CI}$ \\
\hline$\leq 5 \mathrm{mEq} / \mathrm{L}$ & 3011 & 83.94 & $82.7-85.1$ & 724 & 82.2 & $79.6-84.8$ \\
\hline $5.1-5.4 \mathrm{mEq} / \mathrm{L}$ & 420 & 11.71 & $10.7-12.8$ & 85 & 9.7 & $7.7-11.7$ \\
\hline $5.5-5.9 \mathrm{mEq} / \mathrm{L}$ & 135 & 3.76 & $3.2-4.4$ & 53 & 6.0 & $4.5-7.8$ \\
\hline$\geq 6 \mathrm{mEq} / \mathrm{L}$ & 21 & 0.59 & $0.36-0.89$ & 19 & 2.2 & $1.3-3.4$ \\
\hline$<3.5 \mathrm{mEq} / \mathrm{L}$ (hypokalemia) & 66 & 1.84 & $1.4-2.4$ & 90 & 10.2 & $8.3-12.4$ \\
\hline > $5.4 \mathrm{mEq} / \mathrm{L}$ (hyperkalemia) & 156 & 4.3 & $3.7-5.0$ & 72 & 8.2 & $6.5-10.2$ \\
\hline
\end{tabular}

95\% CI, 95\% confidence interval.

* Data reflect the highest potassium levels recorded during hospitalization for each patient, except for the hypokalemia category $(<3.5 \mathrm{mEq} / \mathrm{L})$, which reflects the lowest levels recorded.

All information presented from here on relates to patients in a stable condition (the CHF group). Complete medication information was available for $2650 \mathrm{CHF}$ outpatients with reduced ejection fraction. Within this group, hyperkalemia was assessed as the cause of failure to treat or to achieve the target dose of drugs with proven efficacy that also alter serum potassium concentration: ACEIs, angiotensin II receptor blockers (ARB), and MRAs (Figure 2). Other causes are detailed in Table 1 of the supplementary material. This analysis does not include sacubitril-valsartan because this combination therapy was not initially included in the registry, and information is therefore available for very few patients: this treatment was given to only 14 patients in the Spanish database and was contraindicated in 19 others (no cause recorded). Hyperkalemia was more frequently the cause of failure to treat or to achieve the target dose with MRAs than with the other drugs; this difference was especially marked for failure to treat. In total, 1784 patients (67\%) either did not receive MRA therapy $(n=703)$ or did not achieve the target dose $(n=1081)$; another 402 patients $(5.9 \%)$ were still in the dose-titration phase. Regarding ACEI/ARB therapy, 1494 patients $(56.4 \%)$ either did not receive treatment $(n=204)$ or did not achieve the target dose $(\mathrm{n}=1290)$, while 535 patients $(19.7 \%)$ were still in the dose-titration phase. For MRA therapy, hyperkalemia was the cause of $28.9 \%$ of contraindications, $33.3 \%$ of incidences of intolerance, and $15 \%$ of failures to achieve the target dose. For ACEI/ARB therapy, hyperkalemia accounted for $14.2 \%$ of contraindications and incidences of intolerance and $4.6 \%$ of failures to achieve the target dose. Of the patients who did not receive MRAs or did not achieve the target dose $(\mathrm{n}=1784)$, the cause in $12.8 \%(\mathrm{n}=229)$ was hyperkalemia diagnosed by the treating physician. For ACEI/ARB therapy, the corresponding figure was $5.9 \%(n=88)$ of 1494 patients. Among patients receiving ACEI/ARB and MRA therapy in combination, only a small minority achieved the recommended doses of both drugs. Among the majority of patients who did not, hyperkalemia was the cause in $9.2 \%(234 / 2547)$. 


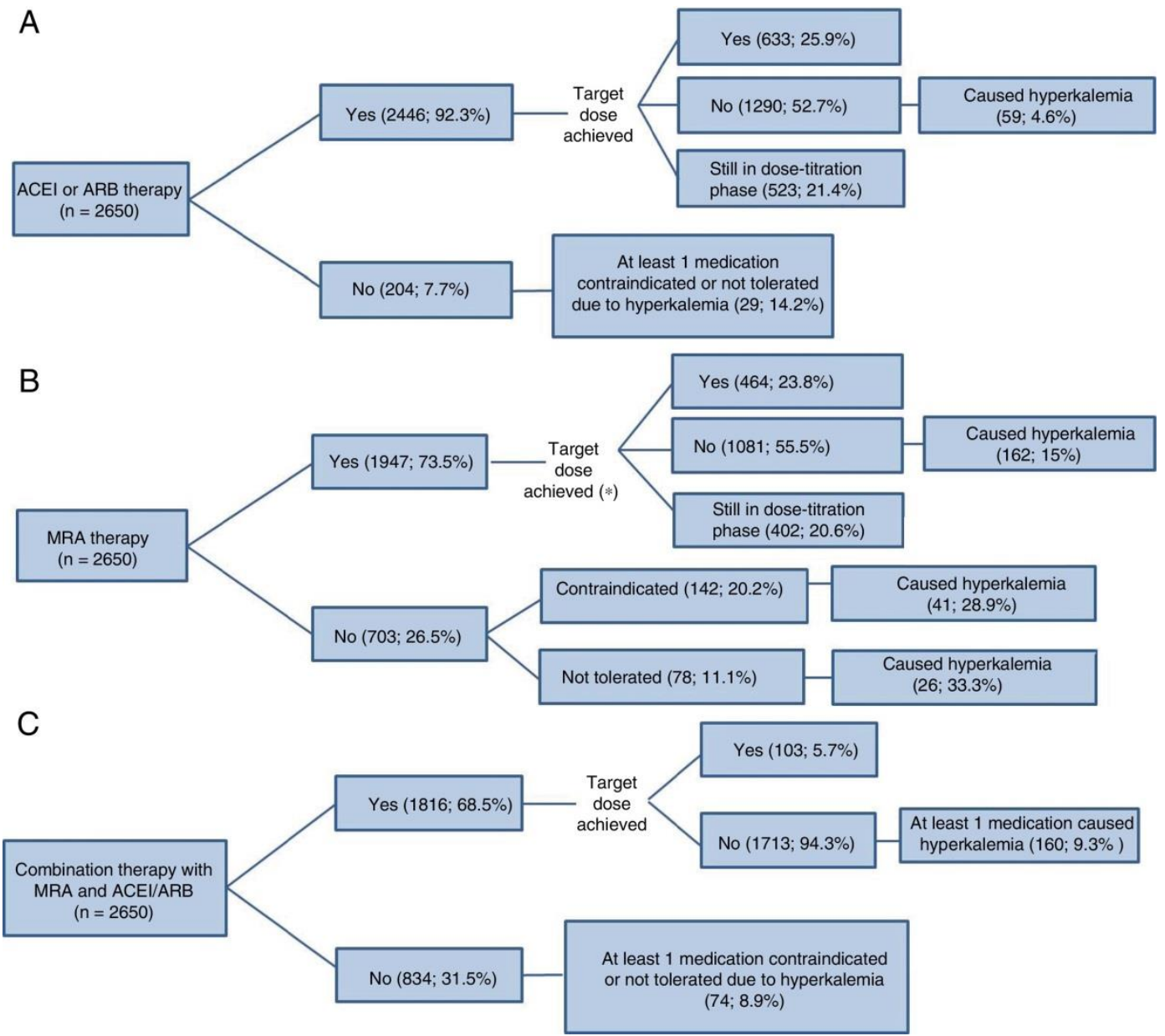

Figure 2. Hyperkalemia as an obstacle to treatment with renin-angiotensin-aldosterone system inhibitors in patients with reduced ejection fraction and under treatment at baseline with (A) ACEIs/ARBs, (B) MRAs, or (C) drugs in both classes. ACEI, angiotensin-converting enzyme inhibitor; ARB, angiotensin II receptor blocker; MRA, mineralocorticoid receptor antagonist. 
Table 1. Target doses for drugs prescribed to heart failure patients with low ejection fraction

\begin{tabular}{lll}
\hline Drug class & Drug & Target dose $\mathrm{mg} / \mathrm{d}$ \\
\hline \multirow{3}{*}{ ACEI } & Ramipril & 10 \\
& Enalapril & 20 \\
& Perindopril & 8 \\
& Lisinopril & 20 \\
ARB & Captopril & 150 \\
& Candesartan & 32 \\
MRA & Losartan & 100 \\
& Valsartan & 320 \\
& Spironolactone & 50 \\
Beta-blockers & Eplerenone & 50 \\
& Canrenone & 50 \\
& Bisoprolol & 10 \\
& Carvedilol & 50 \\
& Metoprolol & 200 \\
& Nebivolol & 10 \\
\hline
\end{tabular}

ACEI, angiotensin-converting enzyme inhibitors; ARB, angiotensin II receptor blocker; MRA, mineralocorticoid receptor antagonist.

Of the $2693 \mathrm{CHF}$ patients with reduced ejection fraction, 291 (10.8\%) had no record of potassiumaltering medication at the baseline visit (group characteristics are presented in Table 2 of the supplementary material). The relationship between relevant drugs taken at baseline and the presence of hyperkalemia at this stage is explored in Table 4, which complements Figure 2. At baseline, approximately $90 \%$ of patients were receiving ACEI or ARB therapy and $73.5 \%$ were receiving MRAs; nevertheless, at this stage only a small proportion (20\%-30\%) had achieved the target dose of any of these drugs. 
Table 4. Relationship of baseline drug therapy with the absence or presence of baseline hyperkalemia $\left(\mathrm{K}^{+}>\right.$ $5.4 \mathrm{mEq} / \mathrm{L}$ ) among chronic heart failure patients with reduced ejection fraction

\begin{tabular}{|c|c|c|c|c|}
\hline & Total $(\mathrm{N}=2402)$ & No $(n=2286)$ & Yes $(n=116)$ & $P$ \\
\hline ACEI therapy & $1539(64.1)$ & $1467(64.2)$ & $72(621)$ & .636 \\
\hline Tyре,\% & & & & .959 \\
\hline Enalapril & 50.42 & 50.44 & 50 & \\
\hline Ramipril & 43.6 & 3.63 & 43.06 & \\
\hline Captopril & 2.6 & 2.59 & 2.78 & \\
\hline Lisinopril & 2.27 & 2.25 & 2.78 & \\
\hline Perindopril & 0.58 & 0.55 & 1.39 & \\
\hline Other & 0.52 & 0.55 & 0 & \\
\hline Target dose achieved & $453(29.4)$ & $429(29.2)$ & $24(33.3)$ & .457 \\
\hline ARB therapy & $678(28.3)$ & $646(28.3)$ & $32(27.6)$ & .868 \\
\hline Type, $\%$ & & & & .973 \\
\hline Candesartan & 34.37 & 34.37 & 34.38 & \\
\hline Losartan & 32.45 & 32.51 & 31.25 & \\
\hline Valsartan & 21.24 & 21.36 & 18.75 & \\
\hline Other & 11.95 & 11.76 & 15.63 & \\
\hline Target dose achieved & $141(20.8)$ & $134(20.7)$ & $7(21.9)$ & .878 \\
\hline ACEI or ARB therapy, \% & 91.5 & 91.7 & 87.8 & .15 \\
\hline MRA therapy & $1763(73.5)$ & $1699(74.4)$ & $64(55.2)$ & $<.001$ \\
\hline Type, \% & & & & $<.001$ \\
\hline Eplerenone & 52.01 & 52.5 & 39.06 & \\
\hline Spironolactone & 47.76 & 47.32 & 59.38 & \\
\hline Other & 0.23 & 0.18 & 1.56 & \\
\hline Target dose achieved & $415(23.5)$ & $408(24.0)$ & $7(10.9)$ & .015 \\
\hline $\begin{array}{l}\text { Sacubitril-valsartan combination } \\
\text { therapy }\end{array}$ & $14(0.6)$ & $13(0.6)$ & $1(0.9)$ & .685 \\
\hline Beta-blocker therapy & $2259(94.1)$ & $2152(94.2)$ & $107(92.2)$ & .377 \\
\hline Tyре, \% & & & & 300 \\
\hline Bisoprolol & 41.5 & 41.5 & 42.1 & \\
\hline Carvedilol & 51.4 & 51.5 & 49.5 & \\
\hline Metoprolol & 0.93 & 0.84 & 2.8 & \\
\hline Nevibolol & 5.7 & 5.7 & 5.6 & \\
\hline Others & 0.49 & 0.51 & 0 & \\
\hline Target dose achieved & $730(32.2)$ & $697(32.4)$ & $33(30.8)$ & .738 \\
\hline
\end{tabular}

ACEI, angiotensin-converting enzyme inhibitors; ARB, angiotensin II receptor blocker; MRA, mineralocorticoid receptor antagonist.

Unless indicated otherwise, data are expressed as no. (\%).

Of the 2402 outpatients with a reduced ejection fraction and a baseline potassium determination, complete follow-up information was available on mortality for $86 \%$ and on rehospitalization for $85.3 \%$. The presence of baseline hyperkalemia was not related to the number of patients lost to follow-up or to the type of consultation (health center visit vs telephone call). Patients with or without baseline hyperkalemia showed no statistically significant differences in rehospitalization or mortality, whether these outcomes were analyzed together or separately (Table 5). 
Table 5. Hospitalization and mortality at 1-year follow-up according to the presence or absence of baseline hyperkalemia

\begin{tabular}{lllll}
\hline & Total & Absence & Presence & $P$ \\
\hline & & & & \\
Patients, n & 2402 & 2286 & 116 & $97(83.6)$ \\
Complete mortality follow-up data & $2067(86.1)$ & $1970(86.2)$ & .524 \\
Complete rehospitalization follow-up data & $2050(85.3)$ & $1953(85.4)$ & $97(83.6)$ & .686 \\
Follow-up by telephone & $417(20.7)$ & $396(20.1)$ & $21(21.7)$ & .809 \\
Cumulative 1-year incidence of first & $579(28.2 ;$ & $549(28.1 ;$ & $30(30.9 ;$ & .547 \\
hospitalization, no. (\%; 95\%CI) & $26.3-30.3)$ & $26.1-30.2)$ & $21.9-41.1)$ & \\
Mean rehospitalizations in the population & $0.44 \pm 0.86$ & $0.44 \pm 0.86$ & $0.47 \pm 0.88$ & .565 \\
Mean rehospitalizations among patients with at & $1.56 \pm 0.95$ & $1.53 \pm 0.95$ & $1.53 \pm 0.94$ & .915 \\
least 1 & & & & \\
Cumulative 1-year mortality, no. (\%; 95\%CI) & $167(8.1 ; 6.9-$ & $157(8.0 ; 6.8-$ & $10(10.3 ; 5.1-$ & .409 \\
& $9.3)$ & $9.3)$ & $18.1)$ & \\
Cumulative 1-year incidence of death or & $645(31.20 ;$ & $610(30.96 ;$ & $35(36.1 ;$ & .288 \\
rehospitalization, no. (\%; 95\%CI) & $29.2-33.3)$ & $28.9-33.1)$ & $26.6-46.5)$ &
\end{tabular}

95\% CI, 95\% confidence interval.

Unless indicated otherwise, data are expressed as No. $(\%)$ or mean \pm standard deviation.

\section{Serum potassium category changes between baseline and follow-up}

Data on changes in potassium category between the baseline and 1-year follow-up visits were available for 1431 patients (Table 6 ). Of the total 2862 potassium determinations (2 per patient), $16.8 \%(\mathrm{n}=480)$ were $\mathrm{K}+>5 \mathrm{mEq} / \mathrm{L}$. The potassium category deteriorated (an increase with respect to baseline) in 179 patients $(12.5 \%$; 95\% CI, 10.8-14.3), but only 55 experienced a deterioration requiring a change in treatment $(3.8 \%$; 95\% CI, 2.8-4.9). The risk of potassium category deterioration was associated with several baseline variables in the univariable analysis (Table 7). However, in the age- and sex-adjusted multivariable analysis, a relationship was maintained only for a history of stroke or diabetes mellitus. The variable showing the strongest association in the multivariable analysis was a history of hyperkalemia at baseline, which was inversely associated with the risk of an increase in potassium level at the follow-up visit.

Table 6. Changes in serum potassium concentration from baseline to 1-year follow-up in patients with chronic heart failure

\begin{tabular}{llllll}
\hline Baseline $\mathrm{K}^{+}(\mathrm{mEq} / \mathrm{L})$ & \multicolumn{5}{c}{$\mathrm{K}^{+}$at 1-year follow-up (mEq/L) } \\
\cline { 2 - 6 } & $\leq 5$ & $5.1-5,4$ & $5.5-5,9$ & $\geq 6$ & Total \\
\hline & 1035 & 122 & 27 & 11 & 1195 \\
$\leq 5 \mathrm{mEq} / \mathrm{L}$ & 115 & 36 & 10 & 7 & 168 \\
$5.1-5.4 \mathrm{mEq} / \mathrm{L}$ & 31 & 13 & 10 & 2 & 56 \\
$5.5-5.9 \mathrm{mEq} / \mathrm{L}$ & 6 & 2 & 3 & 1 & 12 \\
$\geq 6 \mathrm{mEq} / \mathrm{L}$ & 1187 & 173 & 50 & 21 & 1431 \\
Total & & & & & \\
\hline
\end{tabular}


Table 7. Association of baseline characteristics with the increase in hyperkalemia at 1-year follow-up of chronic heart failure patients (the 179 patients in a worse potassium category at 1-year follow-up in Table 6)

\begin{tabular}{|c|c|c|c|c|}
\hline & \multicolumn{2}{|c|}{ Univariable analysis } & \multicolumn{2}{|c|}{ Multivariable analysis } \\
\hline & OR $(95 \% \mathrm{CI})$ & $P$ & OR $(95 \% \mathrm{CI})$ & $P$ \\
\hline Baseline hyperkalemia $\left(\mathrm{K}^{+}>5.4 \mathrm{mEq} / \mathrm{L}\right)$ & $0.2(0.05-0.84)$ & .027 & $0.18(0.04-0.73)$ & .017 \\
\hline Age, per y & $1.03(1.02-1.05)$ & $<.001$ & $1.03(1.01-1.04)$ & $<.001$ \\
\hline Sex, women as reference & $0.99(0.68-1.43)$ & .947 & $1.01(0.70-1.46)$ & .947 \\
\hline Smoking & $0.79(0.44-1.4)$ & .413 & & \\
\hline Atrial fibrillation & $0.89(0.63-1.25)$ & .487 & & \\
\hline Diabetes mellitus & $1.61(1.17-2.2)$ & .003 & $1.49(1.08-2.00)$ & .015 \\
\hline Angina & $1.15(0.84-1.58)$ & .375 & & \\
\hline Surgical revascularization & $1.36(0.86-2.16)$ & .187 & & \\
\hline Percutaneous revascularization & $1.12(0.8-1.57)$ & .506 & & \\
\hline Stroke/transient ischemic accident & $1.94(1.23-3.06)$ & .004 & $2.09(1.34-3.26)$ & .001 \\
\hline Peripheral vascular disease & $1.07(0.68-1.68)$ & .781 & & \\
\hline Valve surgery & $1.21(0.72-2.02)$ & .47 & & \\
\hline Hypertension & $0.96(0.7-1.31)$ & .777 & & \\
\hline Venous thromboembolism & $1.54(0.58-4.11)$ & .387 & & \\
\hline Chronic obstructive pulmonary disease & $1.12(0.73-1.7)$ & .603 & & \\
\hline Renal disease & $1.1(0.74-1.63)$ & .631 & & \\
\hline Cancer & $1.66(0.94-2.92)$ & .081 & & \\
\hline Congestive hepatopathy & $1.34(0.59-3.04)$ & .49 & & \\
\hline Depression & $1.12(0.67-1.86)$ & .672 & & \\
\hline Parkinson & $1(1-1)$ & - & & \\
\hline Arthritis & $1.88(0.62-5.74)$ & .265 & & \\
\hline Estimated glomerular filtration rate, per unit & $0.99(0.99-1)$ & .008 & & \\
\hline
\end{tabular}

95\% CI, 95\% confidence interval; OR, odds ratio.

Hyperkalemia as the cause of failure to treat or to achieve the target dose of drugs with proven efficacy

The status of RAAS-inhibitor treatments at 1-year follow-up among patients with normal serum potassium at baseline is presented in Figure 3. A high proportion of the patients who received MRA therapy $(42.1 \%$ ) did not achieve the target dose; in $12.5 \%$ of these patients, the cause was hyperkalemia. 


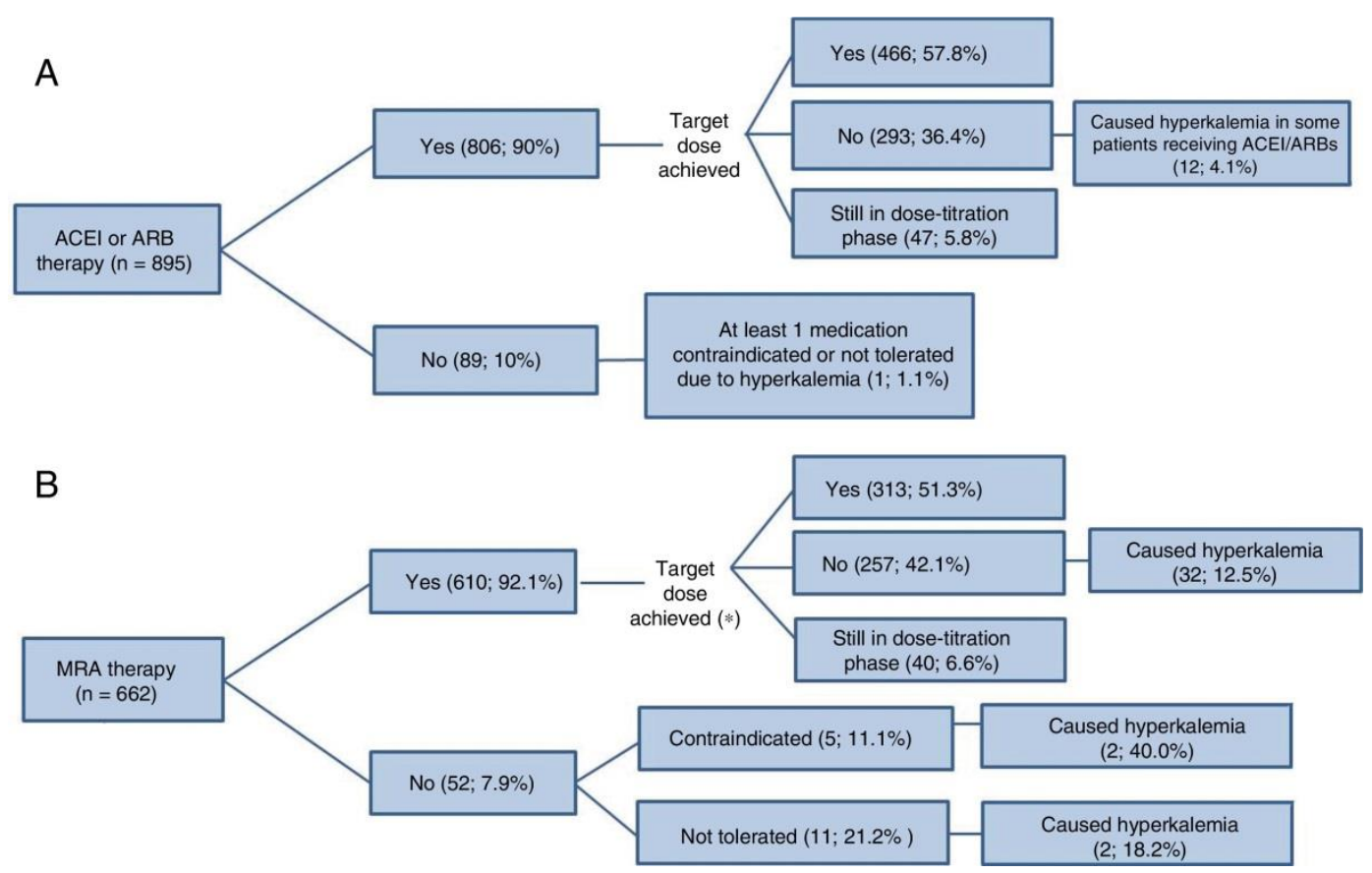

Figure 3. Use of renin-angiotensin-aldosterone system inhibitors in patients with reduced ejection fraction and with no problems attributable to hyperkalemia at the baseline visit.* (A) ACEIs/ARBs, (B) MRAs. ACEI, angiotensin-converting enzyme inhibitor; ARB, angiotensin II receptor blocker; MRA, mineralocorticoid receptor antagonist. *Patients under treatment at baseline who had achieved the target dose or were in the dose-titration phase.

\section{DISCUSSION}

This study reflects the current hyperkalemia situation in centers with some degree of infrastructure dedicated to the chronic treatment of $\mathrm{HF}$ and presents a number of important findings. The development of hyperkalemia is not rare among HF patients with reduced ejection fraction: the condition was detected in $4.3 \%$ of CHF patients, and the proportion was almost double this among acute HF patients at some point during their hospitalization. Moreover, given the importance of potassium monitoring for guiding treatment, the absence of potassium data for $10.8 \%$ of CHF outpatients with reduced ejection fraction shows that this issue does not receive the attention it merits. Hyperkalemia was also a relatively frequent incident cause of medication withdrawal and, above all, failure to achieve the target dose during follow-up.

A recent single-center study in Spain examined 16116 potassium determinations in a group of 2164 patients discharged after an index admission for $\mathrm{HF}^{13}$; hyperkalemia (defined as $\mathrm{K}+>5$ $\mathrm{mEq} / \mathrm{L}$ ) was detected in $7.8 \%$ of determinations. The corresponding figure in our cohort was $17 \%$, an important finding given the established link between even mildly elevated potassium and mortality. ${ }^{13,14,15,16}$ Moreover, the widely accepted hyperkalemia threshold used here $\left(\mathrm{K}^{+}>5.4\right.$ $\mathrm{mEq} / \mathrm{L}$ ) might underestimate the size of the problem; a recent study found that mortality risk is increased even by mild potassium elevation (including to levels between 4.8 and $5.0 \mathrm{mEq} / \mathrm{L}$ ) with respect to comparison values of $4.2-4.4 \mathrm{mEq} / \mathrm{L}$. ${ }^{17}$ 
Previous reports have noted that guideline recommendations for potassium monitoring ${ }^{2}$ are poorly adhered to among patients treated with RAAS inhibitors. In the SCREAM project, potassium was not measured in $24 \%$ of patients during the first year after initiating ACEI/ARB therapy. ${ }^{6}$ These patients had a low hyperkalemia risk, with a history of $\mathrm{HF}$ and potassium-sparing diuretic therapy affecting just $7 \%$ and $4 \%$ of patients, respectively; these parameters were both associated with hyperkalemia risk in the present study, with odds ratios [OR] between 1.5 and 2.0. The hyperkalemia risk in our study population was much higher; all the patients had HF with reduced ejection fraction, and most were taking potassium-altering drugs. ESC guidelines for MRA and ACEI/ARB therapy recommend regular monitoring of blood biochemistry (including potassium), with tests 1 and 4 weeks after therapy initiation or dose changes, repeat tests at 8 and 12 weeks, and follow-up tests every 4 months. ${ }^{2}$ Access to potassium testing during clinical consultations is thus essential for guiding treatment; in the present study, the $10.9 \%$ of patients with no recorded potassium concentration provides a minimum indication of the scope for improvement.

Hyperkalemia was a relatively frequent cause of failure to achieve the recommended RAASinhibitor dose during follow-up, and the frequency was higher for patients already experiencing medication difficulties attributable to hyperkalemia at baseline.

The use of RAAS inhibitors is associated with hyperkalemia even in the highly controlled setting of clinical trials, ${ }^{18,19,20}$ and achieving clinical targets without concomitant hyperkalemia in a trial setting has been attributed to careful potassium monitoring. ${ }^{21}$ Nevertheless, in the absence of diligent potassium monitoring, hyperkalemia remains a common complication in routine clinical practice $^{22}$ and can counter the beneficial effects of RAAS inhibitors (especially MRAs).

The present study confirms that problems with tolerance make it difficult to achieve the RAASinhibitor target dose. This difficulty is seen in clinical trials, despite the diligent monitoring possible in this setting, which is harder to achieve in routine clinical practice. In the CONSENSUS study, only $22 \%$ of patients in the active treatment group achieved the target dose of $40 \mathrm{mg}$ enalapril. ${ }^{23}$ The SOLVD study had a lower target enalapril dose $(20 \mathrm{mg} / \mathrm{d})$ and included a run-in phase to exclude patients with intolerance to low doses; nevertheless, many patients were not taking their medication at the end of the study, and among those patients in the enalapril group who were, $27.5 \%$ were taking a dose below the target. ${ }^{18}$ The more recent PARADIGM trial also included a run-in phase; nevertheless, close to $20 \%$ of participants in the ACEI group abandoned the treatment. ${ }^{24}$ Similar findings have been reported in MRA trials. ${ }^{19,20}$

These findings underline the need to intensify potassium monitoring in patients taking RAAS inhibitors, since patients with sustained elevated potassium have a higher mortality risk than those who maintain normal serum potassium or whose potassium levels normalize during follow-up. ${ }^{13}$ In our study, we did not detect any relationship between serum potassium and the risk of hospitalization or death during follow-up. This likely reflects study limitations related to previous potassium determinations and the difficulty of establishing the temporal relationship between potassium determinations, treatment changes, and outcomes.

Serum potassium concentration increased in $12.5 \%$ of patients during follow-up, and in $3.8 \%$ of patients the increase required the withdrawal of drugs with proven prognostic benefit. In the univariable analysis, the following factors were directly associated with potassium elevation to a higher category than that recorded at baseline: age, diabetes mellitus, a history of stroke or cancer, and glomerular filtration rate. A history of hyperkalemia at baseline served as a warning sign to physicians that 'protected' against further increases during follow-up.

The problem of hyperkalemia in HF patients was already noted in the 2005 ACC/AHA guidelines, particularly in relation to treatment with aldosterone inhibitors; these guidelines proposed 8 ways to minimize the risk. ${ }^{25}$ The current European guidelines emphasize the importance of frequent monitoring of electrolytes and renal function, ${ }^{2}$ in line with other recent recommendations. ${ }^{26}$ The ESC guidelines also comment on the imminent availability of effective potassium-lowering drugs 
(patiromer and sodium zirconium cyclosilicate). These drugs can prevent recurrence of hyperkalemia in HF patients treated with RAAS inhibitors and are set to broaden therapeutic options in these patients in the near future. Improved therapy is also promised by the development of new, nonhormonal MRAs such as finerenone, which are more weakly associated with hyperkalemia than the MRAs currently in use.

To correctly interpret and apply the results of this study, it is important to recognize its limitations. We believe that the study provides a good overview of the problem of hyperkalemia in the clinical management of HF patients with reduced ejection fraction at Spanish centers with a structured patient monitoring program. The corollary of this, however, is that the study is limited by the incompleteness of the information available, including that on potassium determinations, a common problem with this type of analysis. A recent cross-sectional analysis of the Swedish Heart Failure Registry reported an absence of potassium determinations in $39.6 \%$ of patients not taking MRAs, and the proportion was even higher for patients taking this medication $(43.7 \% ; P<.001) .{ }^{27}$ The authors of that study agree with us in considering that the incomplete potassium profiling in many registries is likely a determining factor in treatment underuse.

\section{CONCLUSIONS}

Hyperkalemia is a frequent unwanted outcome of HF therapy with effective drugs. This is a growing concern because hyperkalemia increases the risk of arrhythmias and death in these patients and is itself a risk factor for HF and common comorbidities. This study examined the situation of hyperkalemia in a real-world setting at centers and units with a structured $\mathrm{HF}$ monitoring program. Our results highlight the need to pay more attention to hyperkalemia in HF patients and suggest that certain patient groups require especially intense potassium monitoring.

\section{FUNDING}

This study was cofunded by the European Regional Development Fund (ERDF) through the Instituto de Salud Carlos III.

\section{CONFLICTS OF INTEREST}

M.G. Crespo-Leiro has received consultancy fees from Novartis and Abbot, as well as payments as a speaker and for educational activities and travel expenses from Novartis, Astellas, MSD, Boehringer Ingelheim, and HeartWare. He is also awaiting a grant to his institution from CIBERCV, SEC, and FMM. None of these payments is related to the present study.

J. González-Costello has received consultancy fees from Abbott, Pfizer, and Alnylam, as well as payments for travel expenses, accommodation, and attendance at meetings from Servier, Novartis, Rovi, Bayer, Bristol, Pfizer, Abbott, and Astellas. None of these payments is related to the present study.

A. Bayés-Genís has received consultancy fees from Vifor and is awaiting a grant to his institution from Vifor. None of these payments is related to the present study.

D.A. Pascual-Figal has received consultancy fees from Novartis and Roche. He is awaiting a grant to his institution from Novartis and Roche and has received payments as a speaker and for educational activities and travel expenses from Novartis, Roche, Servier, and MSD. None of these payments is related to the present study.

F. Ridocci-Soriano has received payments as a speaker and for travel expenses, accommodation, and attendance at meetings from Novartis, Servier, and Menarini. None of these payments is related to the present study. 
L.H. Lund has received a grant from Relypsa and consultancy fees from Vifor Pharma and AstraZeneca related to the present study.

J. Muñiz has received consultancy fees and payments for manuscript writing and reviewing the SEC HF Section manuscript.

A.P. Maggioni has received payments from Servier for manuscript writing and is a member of study committees sponsored by Novartis, Bayer, and Fresenius. None of these arrangements is related to the present study.

The remaining authors declare no conflicts of interest.

\section{REFERENCES}

1. Sayago-Silva I, García-López F, Segovia-Cubero J. Epidemiología de la insuficiencia cardiaca en España en los últimos 20 años. Rev Esp Cardiol. 2013;66:649-656.

2. Ponikowski P, Voors AA, Anker SD, et al. 2016 ESC Guidelines for the diagnosis and treatment of acute and chronic heart failure: The Task Force for the diagnosis and treatment of acute and chronic heart failure of the European Society of Cardiology(ESC). Developed with the special contribution of the Heart Failure Association (HFA) of the ESC. Eur J Heart Fail. 2016;18:891-975.

3. Yancy CW, Jessup M, Bozkurt B, et al. 2013 ACCF/AHA guideline for the management of heart failure: a report of the American College of Cardiology Foundation/American Heart Association Task Force on practice guidelines. Circulation.2013;128:e240-e327.

4. Jain N, Kotla S, Little BB, et al. Predictors of hyperkalemia and death in patients with cardiac and renal disease. Am J Cardiol. 2012;109:1510-1513.

5. Acker CG, Johnson JP, Palevsky PM, et al. Hyperkalemia in hospitalized patients: causes, adequacy of treatment, and results of an attempt to improve physician compliance with published therapy guidelines. Arch Intern Med. 1998;158:917-924.

6. Bandak G, Sang Y, Gasparini A, et al. Hyperkalemia after initiating renin-angioten-sin system blockade: The Stockholm Creatinine Measurements (SCREAM) Project. JAm Heart Assoc. 2017;6:e05428.

7. Sarwar CMS, Papadimitriou L, Pitt B, et al. Hyperkalemia in heart failure. J Am Coll Cardiol. 2016;68:1575-1589.

8. Go AS, Chertow GM, Fan D, McCulloch CE, Hsu CY. Chronic kidney disease and the risks of death, cardiovascular events, and hospitalization. N Engl J Med. 2004;351:1296-1305.

9. Vardeny $\mathrm{O}, \mathrm{Wu} \mathrm{DH}$, Desai $\mathrm{A}$, et al. Influence of baseline and worsening renal function on efficacy of spironolactone in patients with severe heart failure: insights from RALES (Randomized Aldactone Evaluation Study). J Am Coll Cardiol. 2012;60:2082-2089.

10. Crespo-Leiro MG, Segovia-Cubero J, González-Costello J, et al. Adecuación en España a las recomendaciones terapéuticas de la guía de la ESC sobre insuficiencia cardiaca: ESC Heart Failure Long-term Registry. Rev Esp Cardiol. 2015;68:785-793.

11. Crespo-Leiro MG, Anker SD, Maggioni AP, et al. European Society of Cardiology Heart Failure LongTerm Registry (ESC-HF-LT): 1-year follow-up outcomes and differences across regions. Eur J Heart Fail. 2016;18:613-625.

12. KDIGO 2012 Clinical practice guideline for the evaluation and management of chronic kidney disease. Disponible en: https://www.sciencedirect.com/journal/kidney-international-supplements/vol/3/issue/1. Consulted 9 May 2019.

13. Núñez J, Bayés-Genís A, Zannad F, et al. Long-term potassium monitoring and dynamics in heart failure and risk of mortality. Circulation. 2018;137:1320-1330.

14. Luo J, Brunelli SM, Jensen DE, Yang A. Association between serum potassium and outcomes in patients with reduced kidney function. Clin J Am Soc Nephrol.2016;11:90-100.

15. Einhorn LM, Zhan M, Hsu VD, et al. The frequency of hyperkalemia and its significance in chronic kidney disease. Arch Intern Med. 2009;169:1156-1162.

16. McMahon GM, Mendu ML, Gibbons FK, Christopher KB. Association between hyperkalemia at critical care initiation and mortality. Intens Care Med. 2012;38:1834-1842.

17. Aldahl M, Jensen AC, Davidsen L, et al. Association of serum potassium levels with mortality in chronic heart failure patients. Eur Heart J. 2017;38:2890-2896.

18. The SOLVD Investigators, Yusuf S, Pitt B, Davis CE, Hood WB, Cohn JN. Effect of enalapril on survival in patients with reduced left ventricular ejection fractions and congestive heart failure. $N$ Engl $J$ Med. 1991;325:293-302

19. Zannad F, McMurray JJ, Krum H, et al. Eplerenone in patients with systolic heart failure and mild symptoms. N Engl J Med. 2011;364:11-21. 
20. Pitt B, Remme W, Zannad F, et al. Eplerenone, a selective aldosterone blocker, inpatients with left ventricular dysfunction after myocardial infarction. N Engl J Med. 2003;348:1309-1321.

21. Pitt B, Bakris G, Ruilope LM, Di Carlo L, Mukherjee R. EPHESUS investigators. Serum potassium and clinical outcomes in the Eplerenone Post-Acute Myocardial Infarction Heart Failure Efficacy and Survival Study (EPHESUS). Circulation. 2008;118:1643-1650.

22. Juurlink DN, Mamdani MM, Lee DS, et al. Rates of hyperkalemia after publication of the Randomized Aldactone Evaluation Study. N Engl J Med. 2004;351:543-551.

23. CONSENSUS Trial Study Group. Effects of enalapril on mortality in severe congestive heart failure: results of the Cooperative North Scandinavian Enalapril Survival Study (CONSENSUS). N Engl J Med. 1987;316:1429-1435.

24. McMurray JJ, Packer M, Desai AS, et al. Angiotensin-neprilysin inhibition versus enalapril in heart failure. N Engl J Med. 2014;371:993-1004.

25. Hunt SA, Abraham WT, Chin MH, et al. ACC/AHA 2005 guideline update for the diagnosis and management of chronic heart failure in the adult: a report of the American College of Cardiology/American Heart Association Task Force on Practice Guidelines (Writing Committee to Update the 2001 Guidelines for the Evaluation and Management of Heart Failure). Circulation. 2005;112:e154-e235.

26. Real J, Cowles E, Wierzbicki AS. Chronic heart failure in adults: summary of updated NICE guidance. BMJ. 2018;362:k3646.

27. Savarese G, Carrero JJ, Pitt B, et al. Factors associated with underuse of mineralo-corticoid receptor antagonists in heart failure with reduced ejection fraction: an analysis of 11,215 patients from the Swedish Heart Failure Registry. Eur J Heart Fail.2018;20:1326-1334 